\title{
Síndrome congênita do Zika vírus - um novo desafio ao odontopediatra: uma revisão bibliográfica
}

\author{
Zika virus congenital syndrome - a new challenge to the pediatric dentist: a bibliographic \\ review
}

Síndrome congénito del virus Zika - un nuevo reto para el dentista pediátrico: una revisión bibliográfica

Priscila Correia Bezerra de Menezes ${ }^{1 *}$, Yohana de Oliveira Ponte ${ }^{1}$, Daniela Cavalcante Girão1, Amanda de Albuquerque Vasconcelos ${ }^{1}$, Luciana de Araujo Martins ${ }^{1}$, Karla Aguiar Cabral Cunha', Maria Thais Aragão de Carvalho ${ }^{1}$, Caroline Pereira Pessoa ${ }^{1}$, Karla Emília Salatiel de Alencar $^{1}$, Italo Sarto Carvalho Rodrigues².

\section{RESUMO}

Objetivo: Discorrer sobre os atrasos de desenvolvimento dos bebês acometidos pela Síndrome Congênita do Zika, bem como suas características craniofaciais, avaliando a importância do diagnóstico precoce das dificuldades para estabelecer um atendimento odontológico individualizado.Revisão Bibliográfica: Nos últimos anos, devido ao aumento de crianças nascidas com microcefalia no Brasil, sobretudo na região Nordeste, iniciou-se uma investigação. Foram percebidas crianças acometidas pelo Zika vírus, com atrasos no desenvolvimento e alterações das características craniofaciais.Assim, torna-se fundamental enfatizar o diagnóstico precoce e a participação de uma equipe multiprofissional, incluindo o cirurgião-dentista, para uma boa condução do tratamento multidisciplinar visando amenizar os prejuízos causados pela infecção do Zika vírus. Considerações Finais: É importante a avaliação da população afetada a fim de conhecer os achados clínicos do desenvolvimento causado pela malformação, direcionando a estimulação precoce com equipe multidisciplinar. Além disso, esses pacientes são considerados de alto risco para o desenvolvimento de doenças bucais e é necessário que o Odontopediatra realize as consultas preventivas, orientando e ressaltando uma higiene bucal adequada, com envolvimento familiar. Dessa forma, existe mais facilidade para propor a melhor intervenção odontológica, contribuindo para uma melhor qualidade de vida deste paciente.

Palavras-chave: Zika vírus, Microcefalia, Odontopediatria.

\begin{abstract}
Objective: To discuss the development delays of babies affected by Zika's congenital syndrome, as well as their craniofacial characteristics, evaluating the importance of early diagnosis of difficulties in establishing individual dental care. Bibliographic Review: In recent years, due to the increase in children born with microcephaly in Brazil, especially in the Nordeste, an investigation has begun. Children affected by Zika virus with developmental delays and changes in craniofacial characteristics were noticed. Thus, it is essential to emphasize the early diagnosis and the participation of a multidisciplinary team, including the dentist, for a good conduction of multidisciplinary treatment aiming at alleviate the damage caused by Zika virus infection. Conclusions: It is important to evaluate the affected population in order to know the clinical findings of the development caused by malformation, directing early stimulation with a multidisciplinary team. In addition, these patients are considered high risk for the development of oral diseases and it is necessary for the pediatric dentist to perform preventive consultations, guiding and emphasizing an adequate oral hygiene, with family involvement. Thus, it is easier to propose the best dental intervention, contributing to a better quality of life for this patient.
\end{abstract}

Key words: Zika Virus, Microcephaly, Pediatric Dentistry.

\footnotetext{
${ }^{1}$ Faculdade São Leopoldo Mandic (SLMANDIC), Fortaleza- Ceará. *E-mail: priscilacbm@hotmail.com

${ }^{2}$ Faculdade de Odontologia de Piracicaba (UNICAMP), Piracicaba- São Paulo.
} 


\section{RESUMEN}

Objetivo: Discutir los retrasos en el desarrollo de los bebés afectados por el síndrome congénito de Zika, así como sus características craneofaciales, evaluando la importancia del diagnóstico precoz de las dificultades para establecer una atención dental individual. Revisión Bibliográfica: En los últimos años, debido al aumento de niños nacidos con microcefalia en Brasil, especialmente en el Nordeste, ha comenzado una investigación. Se notaron niños afectados por el vírus del Zika con retrasos en el desarrollo y cambios en las características craneofaciales. Por lo tanto, es esencial enfatizar el diagnóstico temprano y la participación de un equipo multidisciplinario, incluido el dentista, para una buena conducción del tratamiento multidisciplinario dirigido a aliviar el daño causado por la infección por el vírus Zika. Consideraciones finales: Es importante evaluar la población afectada para conocer los hallazgos clínicos del desarrollo causado por la malformación, dirigiendo la estimulación temprana con un equipo multidisciplinario. Además, estos pacientes son considerados de alto riesgo para el desarrollo de enfermedades bucales y es necesario que el dentista pediátrico realice consultas preventivas, guiando y enfatizando una higiene bucal adecuada, con la participación de la familia. De esta manera, es más fácil proponer la mejor intervención dental, contribuyendo a una mejor calidad de vida para este paciente.

Palabras clave: Virus Zika, Microcefalia, Odontología Pediátrica.

\section{INTRODUÇÃO}

Nos últimos anos, neuropediatras de Recife perceberam alterações radiológicas sugestivas de infecção congênita, como calcificações, desordem do desenvolvimento cortical e ventriculomegalia, devido o grande número de bebês acometidos, os profissionais alertaram sobre uma epidemia de microcefalia. Diante desse contexto, percebeu-se uma doença exantemática aguda no Brasil que tem como agente etiológico o vírus Zika (MIRANDA-FILHO DB, et al., 2016).

Em 1947, o vírus Zika foi encontrado em macacos rhesus, durante pesquisas sobre o vírus da febre amarela, recebendo este nome em referência à floresta em Uganda, na África. Em seguida, identificaram infecções em humanos, passando a ser isolado em países da África e da Ásia, até que em 2014 o vírus foi notificado em casos na llha de Páscoa, no Chile, marcando a chegada às Américas (ZANLUCA C, et al., 2015).

O vírus Zika é um arbovírus, pertencente ao gênero do Flavivírus, família Flaviviridae e apresenta o ácido ribonucleico como seu material genético. É transmitido principalmente pelos mosquitos Aedes aegyptie Aedes albopictus, tendo registros de transmissão também por fluidos corporais como sangue, sêmen, urina e saliva (PEREIRA SMS, et al., 2017). A informação da transmissão vertical de Zika da mãe para o feto é recente. Em 2013, foram descritas duas mães e seus recém-nascidos infectados por Zika na Polinésia Francesa, infecção que pode ter ocorrido intra-útero ou no momento do parto (SCHULER-FACCINI L, et al., 2016).

Em 2015, com a confirmação dos primeiros casos de febre por Zika no Brasil, inicialmente no Nordeste, observou-se uma rápida dispersão do vírus para as outras regiões do país, e seguiu-se o aumento expressivo das notificações de recém-nascidos com microcefalia no Sistema de Informação de Nascidos Vivos (SINASC), além dos registros de abortos espontâneos e natimortos (KINDHAUSER MK et al., 2016).

O Brasil foi o primeiro país de grande porte a vivenciar a rápida disseminação do vírus, o que fez com que suas autoridades sanitárias fossem pioneiras em comunicar a situação de emergência à Organização Mundial de Saúde (OMS) e a confirmar o envolvimento do Zika vírus na causalidade da microcefalia (HENRIQUES CMP, et al., 2016).

A infecção pelo vírus Zika durante o desenvolvimento embrionário e fetal resulta em um quadro com características distintas daquelas observadas na microcefalia decorrente de outras infecções congênitas, que tem sido descrito como síndrome da infecção congênita pelo vírus Zika (EICKMANN SH et al., 2016).

Esta nova síndrome de malformação congênita inclui, além de microcefalia e lesão cerebral fetal, uma série de alterações no desenvolvimento como manifestações musculoesqueléticas, oculares, craniofaciais, geniturinárias e pulmonares (ALVARADO MG e SCHWARTZ DA, 2017). 
O estudo de Leite CN e Varellis MLZ (2016) relatou que crianças com microcefalia no Brasil apresentavam alterações bucais como micrognatia, disfagia, bruxismo, atraso na erupção dentária, doenças periodontais, cárie dentária, maloclusão e traumatismos dentários.

Assim, com o surgimento de um grande número de crianças acometidas pela Síndrome Congênita do Zika nos últimos anos, o objetivo deste trabalho é discorrer, por meio de uma revisão de literatura, sobre os atrasos de desenvolvimento dos bebês acometidos pela Síndrome Congênita do Zika, bem como suas características craniofaciais, avaliando a importância do diagnóstico precoce das dificuldades a fim de estabelecer um atendimento odontológico individualizado.

\section{REVISÃO BIBLIOGRÁFICA}

Em 2015, devido ao surto de uma doença semelhante a dengue, pesquisadores isolaram o Zika vírus de soros de pacientes atendidos em serviços de emergência em cidades do Nordeste brasileiro. Pouco depois, pesquisadores de outros estados do Brasil encontraram o vírus em pacientes com quadros semelhantes, constatando a transmissão autóctone e a ocorrência de infecções por Zika no Brasil (CARDOSO CW, et al., 2015).

Ainda nesse mesmo ano, médicos de alguns estados do Nordeste, perceberam e notificaram o aumento de casos de microcefalia em recém-nascidos e a Síndrome de Guillain-Barré em adultos, e esses pacientes tinham em comum que foram acometidos após a infecção pelo Zika. (OLIVEIRA MELO AS, et al., 2016).

Os sintomas podem durar de poucos dias até uma semana, geralmente são brandos, caracterizados por início súbito de quadro febril, artralgia, rash maculopapular ou conjuntivite não purulenta, no entanto, é importante destacar que a maioria das pessoas infectadas pelo Zika vírus são assintomáticas (DUFFY MR, et al., 2009).

Segundo o CDC (Center for Desease Control and Prevention) deve-se suspeitar do diagnóstico de Zika quando dois ou mais sintomas estão presentes durante ou no período de até duas semanas de estada em área endêmica pelo vírus (STAPLES JE, et al., 2016).

Não há vacinas, medicamentos ou agentes imunobiológicos de uso antenatal ou perinatal para impedir a infecção vertical pelo Zika (FEITOSA IM, et al., 2016). Sendo assim, recomenda-se o uso de medidas de prevenção contra a picada do vetor, como o uso de repelentes, mosquiteiros, telas e roupas longas (SCHULER-FACCINI L, et al., 2016). Além disso, identificou-se que o vírus pode permanecer viável por até 6 meses no sêmen, independente de manifestações clínicas. Dessa forma, o uso de preservativos nas relações sexuais deve ser ressaltado (MOORE CA, et al., 2016).

Por meio de materiais biológicos como líquor, soro, líquido amniótico, saliva e urina, realiza-se o diagnóstico laboratorial, com testes de biologia molecular e sorológicos (FAYE O, et al., 2013). Os resultados são obtidos a partir da amplificação do RNA viral através da reação em cadeia de polimerase de transcrição reversa (RT-PCR) (MUSSO D, et al., 2015).

Ademais, nos casos de infecção congênita por Zika, sugere-se a realização do exame imuno-histoquímico na placenta e no cordão umbilical. Em caso de óbito fetal, o diagnóstico consiste na realização de RT-PCR e imuno-histoquímica nos tecidos fetais (STAPLES JE, et al., 2016).

Após a detecção do surto de pacientes acometidos pelo Zika vírus, provavelmente causando o aumento de casos de microcefalia, buscou-se investigar esta associação causal com vários especialistas, inclusive médicos geneticistas (FEITOSA IM, et al., 2016).

O nexo causal foi feito pelo Instituto Evandro Chagas (IEC), do Ministério da Saúde, ao isolar o Zika do cérebro e ao fazer a detecção desse vírus no líquido cefalorraquidiano (LCR), cérebro e em várias vísceras de um recém-nascido que foi a óbito logo após o nascimento (KINDHAUSER MK, et al., 2016).

Posteriormente, esses resultados foram reforçados com a detecção de anticorpos IgM para Zika no LCR de 12 crianças que nasceram com microcefalia. Todos os exames para outros agentes infecciosos 
associados, como toxoplasmose, rubéola, citomegalovírus, herpes simples, bem como para dengue e Chikungunya, foram negativos (OLIVEIRA CS e VASCONCELOS PFC, 2016).

Outra contribuição importante foi a identificação do Zika vírus em amostras de líquido amniótico de duas gestantes da Paraíba, com histórico de doença exantemática e fetos com microcefalia detectados através de exame de ultrassonografia (OLIVEIRA MELO AS, et al., 2016).

Somando a essas evidências, foi também identificado o genoma do Zika vírus em células da placenta em um aborto na $8^{\text {a }}$ semana de gestação, por meio de técnicas de RT-PCR em tempo real, reforçando o potencial da transmissão placentária (OLIVEIRA CS e VASCONCELOS PFC, 2016).

Foram confirmadas pelo CDC (Center for Desease Control and Prevention), a presença do vírus por RTPCR e imuno-histoquímica no tecido cerebral de quatro recém-nascidos com microcefalia e graves malformações cerebrais que foram a óbito após o nascimento e nas placentas de fetos abortados na $12^{\underline{a}}$ semana de gestação (MARTINES RB, et al., 2016).

Mlakar J, et al. (2016) identificaram o genoma viral no cérebro e na placenta de um feto que sofreu aborto na $32^{\text {a }}$ semana de gestação, que apresentou inúmeras lesões cerebrais e retardo de crescimento intrauterino detectados a partir da 29a semana de gestação, confirmando o neurotropismo do vírus com possível persistência viral no tecido cerebral e grave comprometimento placentário.

Costello A, et al. (2016) apontam que o Zika vírus é neurotrópico, ou seja, tem capacidade de alterar não apenas células progenitoras neurais, mas também neurônios e outras células cerebrais. Este dano cerebral direto induzido pelo vírus pode ser responsável por muitas das malformações observadas no casos da Síndrome Congênita do Zika como diminuição da atividade fetal, contraturas articulares, anormalidades craniofaciais, malformações dos membros e artrogripose, hipoplasia e criptorquidemia.

Até o momento, compreende-se que o Zika vírus pode afetar conceptos em diferentes períodos da gestação e a Síndrome Congênita do Zika (SZC) pode provocar defeitos congênitos, alterações neurossensoriais e positividade de reações virológicas e sorológicas e de acordo com o período de exposição intrauterina, o grau desses defeitos sofrem variação (MOORE CA, et al., 2016).

As alterações podem ocorrer em diferentes graus. Os casos mais graves no primeiro e início do segundo trimestres da gestação devido à infecção vertical e os casos mais leves apresentam danos estruturais mais discretos (SCHULER-FACCINI L, et al., 2016).

A infecção fetal no primeiro trimestre de gestação pode resultar em reabsorção do embrião, aborto, prematuridade, anomalias de desenvolvimento, doença aguda aparente ao nascimento ou logo após este, ou infecção assintomática no período neonatal com ou sem persistência e desenvolvimento de sequelas tardias (MUSSI-PINHATA MM e YAMAMOTO AY, 1999).

Algumas alterações são características e podem ser observadas durante o exame físico dos recémnascidos acometidos pela Síndrome Congênita do Zika, como uma desproporção craniofacial. Além disso, outras alterações podem ser percebidas, como acentuada protuberância óssea occipital, fontanelas fechadas ao nascer, excesso de pele ou dobras de pele no escalpo, além de hérnia umbilical (EICKMANN SH, et al., 2016).

A microcefalia ocorre quando a medida do perímetro cefálico é menor que menos $2(-2)$ desvios-padrão abaixo da média específica para o sexo e idade gestacional. Já na microcefalia severa, o perímetro cefálico é menor que menos 3 (-3) desvios-padrão (ASHWAL S, et al., 2009).

Segundo os critérios da Organização Mundial de Saúde (OMS), o recém-nascido com 37 semanas ou mais de idade gestacional, apresentando medida do perímetro cefálico menor ou igual a $31,5 \mathrm{~cm}$ para meninas e $31,9 \mathrm{~cm}$ para meninos (o equivalente a menor que -2 desvios-padrão para a idade e sexo), teriam microcefalia (OMS, 2016).

Assim, a microcefalia pode ser considerada como uma condição neurológica em que o cérebro é subdesenvolvido e as fontanelas, espaços abertos entre os ossos que permitirão que o cérebro cresça sem

REAS/EJCH | Vol.12(3) | e2544 | DOI: https://doi.org/10.25248/reas.e2544.2020 Página 4 de 8 
haver compressão das estruturas, se fecham com prematuridade, sendo perceptível uma criança com a cabeça menor do que as de outras crianças da mesma idade e sexo (LEITE CN e VARELLIS MLZ, 2016).

É imprescindível que a medida e a interpretação do perímetro cefálico estejam corretas para um diagnóstico preciso. Em algumas situações, essa medida não indica um formato e tamanho anormal do crânio. Assim, posiciona-se uma fita métrica flexível e não elástica, na testa, passando acima das orelhas e pela porção mais proeminente da parte posterior do crânio, mede-se o diâmetro do crânio em sua maior circunferência. Para evitar diagnósticos errôneos, recomenda-se a repetição dessa medida após um ou mais dias do nascimento, principalmente na presença de cavalgamento de suturas ao nascer (NUNES ML, et al., 2016).

Alguns lactentes expostos ao Zika vírus intra-útero, nasceram com medidas de perímetro cefálico normal e apresentaram microcefalia pós-natal ou hidrocefalia (neste caso com macrocefalia), desse modo, mesmo os bebês que ao nascer apresentem perímetro cefálico normal devem ser acompanhados clinicamente com atenção às alterações que podem ocorrer (VAN DER LINDEN V, et al., 2016).

Convém ressaltar que a ausência de microcefalia congênita não afasta a possibilidade de infecção antenatal por Zika e de Síndrome Congênita do Zika (FEITOSA IM, et al., 2016). De fato, existem evidências de que o uso de critérios padrão para microcefalia pode ser insuficiente no diagnóstico de todos os casos de Síndrome Congênita do Zika. Em estudo realizado no Brasil, observou- se que um em cada cinco recémnascidos com a síndrome provável ou definida apresentou valores de circunferência cefálica dentro do intervalo de referência (FRANÇA GV, et al., 2016).

Durante a gestação, utiliza-se a ultrassonografia obstétrica a cada três a quatro semanas para acompanhar o crescimento fetal e cerebral, além de possibilitar a detecção precoce de possíveis anormalidades do Sistema Nervoso Central. No período pós-natal, para investigação inicial de anormalidades sugere-se a ultrassonografia transfontanelar para perímetro cefálico igual ou inferior a $32 \mathrm{~cm}$. Na presença de anormalidades detectadas pelo ultrassom transfontanelar e para os recém-nascidos que apresentam microcefalia grave ( -3 desvios-padrão), deve ser realizada a tomografia computadorizada do cérebro ou a ressonância magnética (PETERSEN EE, et al., 2016).

Mesmo após a microcefalia ser instalada e diagnosticada pela ultrassonografia pré-natal, a circunferência cefálica do feto continua a crescer até o nascimento, porém com velocidade de crescimento menor que o esperado. Além disso, este crescimento dá-se de forma não linear, ou seja, nas idades gestacionais mais próximas do nascimento a velocidade de crescimento tende a diminuir (SOUZA ASR, et al., 2016).

Entre as anormalidades neurológicas relacionadas a microcefalia destacam-se a hipertonia global grave com hiper-reflexia, irritabilidade, hiperexcitabilidade, choro excessivo, distúrbio de deglutição, déficit intelectual, epilepsia, paralisia cerebral, atraso no desenvolvimento motor e de linguagem, além de desordens oftalmológicas, auditivas, cardíacas, renais e do trato urinário (BRUNONI D, et al., 2016).

No período neonatal, algumas crianças já apresentam crises convulsivas que se tornam frequentes e mais evidentes a partir dos três meses de idade e os espasmos epilépticos são o tipo mais comum (EICKMANN $\mathrm{SH}$, et al., 2016). Após o nascimento, ainda no primeiro trimestre de vida, já é possível identificar sinais de lesões cerebrais graves a partir de anormalidades presentes no tônus muscular, nos reflexos primitivos, nas reações posturais e na motricidade voluntária (ALMEIDA FC, et al., 2014).

Cerca de $90 \%$ das microcefalias estão associadas com retardo mental. O tipo e o nível de gravidade da sequela variam a cada caso. Não há tratamento específico para a microcefalia. Existem ações de suporte que podem auxiliar no desenvolvimento do bebê e da criança, preconizado pelo Sistema Único de Saúde (ABREU TT, et al., 2016). Dentre as características de relevância dos pacientes microcéfalos para o atendimento odontológico destacam-se o atraso no desenvolvimento, hipotonia, microstomia, dimorfismo facial, micrognatia, retrognatia, palato anormal e amplo espaço entre os dentes (SIQUEIRA WL, et al., 2016).

Além disso, esses pacientes têm alto risco de desenvolverem doenças bucais, isso pode ser atribuído ao fato de apresentarem atraso nas habilidades motoras devido à hipotonia muscular, impedindo a realização de 
cuidados bucais adequados, tornando o paciente dependente de um cuidador para a realização da higiene oral, que em alguns casos, pode ser dificultada pela presença de microstomia (NIMMAKAYALU M, et al., 2011).

Morava E, et al. (2007) destacam que entre os dismorfismos faciais encontrados nos pacientes microcéfalos estão braquicefalia, hipoplasia da face média, testa estreita e plana, face plana, lábio fino, região malar plana, nariz amplo e curto, pescoço curto com pele enrugada, sobrancelhas altas,ponte nasal e terço médio achatado, crânio em forma de caixa, testa proeminente, fontanela anterior aberta, ponta nasal bulbosa, orelhas pequenas e protuberantes, entre outros. Esta condição associada à hipotonicidade da língua levam os lábios a serem frequentemente banhados por saliva, podendo causar queilite angular, irritação e fissuras nos cantos labiais, facilitando a instalação de processos infecciosos (MORAVA E, et al., 2007).

É importante diagnosticar precocemente as dificuldades e atrasos de desenvolvimento das crianças acometidas pela Síndrome Congênita do Zika para o estabelecimento de um plano individual e direcionado a estimulação precoce. A estimulação da motricidade orofacial nos primeiros meses de vida dos bebês com microcefalia deve-se basear na melhora das funções motoras orais como sucção, mastigação, deglutição, respiração e fonação, favorecendo assim, o desenvolvimento harmônico e favorável da região orofacial (BRASIL, 2016). A conduta durante o tratamento odontológico deve incluir anamnese detalhada, com dados sobre a presença de alterações relacionadas à microcefalia como, convulsões, retardo mental, atraso na aquisição da fala, dificuldade de deglutição e sucção, entre outros aspectos (LEITE CN e VARELLIS MLZ, 2016).

As consultas devem ser rápidas, com individualização da abordagem e do posicionamento para maior conforto do paciente. Para reduzir a dificuldade de deglutição, sugere-se posicionar o paciente de forma inclinada, para não o deixar totalmente deitado. Além disso, devem ser evitados movimentos bruscos, estimulação sonora e visual, uma vez que essas situações podem desencadear reflexos comportamentais do indivíduo. É essencial na elaboração do plano de tratamento, o controle dos fatores etiológicos primários da doença cárie e demais alterações bucais, sendo necessário um treinamento em higiene bucal com o paciente, na presença dos cuidadores (LEITE CN e VARELLIS MLZ, 2016).

Portanto, conhecer as disfunções associadas à microcefalia e os principais problemas orais do paciente auxiliam no direcionamento dos cuidados com o tratamento, visando obter uma melhor gestão técnica e comportamento clínico durante o tratamento (MORO JS, et al., 2019).

É importante atuar para a resolução de alterações de deglutição, fala e comunicação desses pacientes. Sendo assim, a participação de uma equipe multiprofissional é imprescindível, sobretudo a interação entre o cirurgião-dentista e o fonoaudiólogo. Além disso, para assegurar uma boa condução do tratamento odontológico, é fundamental o contato com o médico (LEITE CN e VARELLIS MLZ, 2016).

Cuidados especiais devem ser direcionados aos familiares responsáveis pela condução da criança aos serviços especializados. É preciso considerar a necessidade de suporte e apoio médico, educacional e psicológico que essas famílias devem ter assegurados diante dos prejuízos do desenvolvimento que possivelmente acometerão as crianças afetadas pelo Zika (BRUNONI D, et al., 2016).

\section{CONSIDERAÇÕES FINAIS}

É importante a avaliação da população afetada a fim de conhecer os achados clínicos do desenvolvimento, direcionando a estimulação precoce com equipe multidisciplinar, de forma a atender as especificidades dessas crianças, preferencialmente no início da vida, período crítico para a redução do nível de comprometimento do desenvolvimento neuropsicomotor, causado pela malformação. Além disso, esses pacientes são considerados de alto risco para o desenvolvimento de doenças bucais e é necessário que 0 Odontopediatra conheça o bebê com a Síndrome Congênita do Zika e, realize as consultas preventivas, orientando e ressaltando uma higiene bucal adequada, com envolvimento familiar. Dessa forma, existe mais facilidade para propor a melhor intervenção odontológica, contribuindo para uma melhor qualidade de vida deste paciente.

REAS/EJCH | Vol.12(3) | e2544 | DOI: https://doi.org/10.25248/reas.e2544.2020 Página 6 de 8 


\section{REFERÊNCIAS}

1. ABREU TT, et al. Crianças com microcefalia associada a infecção congênita pelo vírus Zika: características clínicas e epidemiológicas num hospital terciário. Rev Ciênc. Méd. Biol., 2016; 15(3): 426-433.

2. ALMEIDA FC, et al. Protocolo de avaliação clínica da disfagia pediátrica (PAD-PED). Barueri: Pró-Fono; 2014.

3. ALVARADO MG, SCHWARTZ DA. Zika virus infection in pregnancy, microcephaly, and maternal and fetal health: what we think, what we know, and what we think we know. Arch Pathol Lab Med., 2017; 141(1): 26-32.

4. ASHWAL S, et al. Michelson D, Plawner L, Dobyns WB. Practice Parameter.Evaluation of the child with microcephaly (an evidence - based review). Neurology, 2009; 73:887-97.

5. BRASIL. Ministério da Saúde. Secretaria de Atenção à Saúde. Diretrizes de estimulação precoce: crianças de zero a 3 anos com atraso no desenvolvimento neuropsicomotor decorrente de microcefalia. Brasília: Ministério da Saúde, 2016.

6. BRUNONI D, et al. Microcefalia e outras manifestações relacionadas ao vírus Zika: impacto nas crianças, nas famílias e nas equipes de saúde. Ciência \& Saúde Coletiva, 2016; 21(10): 3297-3302.

7. CAMPOS GS, et al. Zika virus outbreak, Bahia, Brazil. Emerg Infect Dis., 2015; 21: 1885-6.

8. CARDOSO CW, et al. Outbreak of acute exanthematous illness associated with Zika, Chikungunya, and dengue viruses, Salvador, Brazil [letter]. Emerg Infect Dis., 2015; 21(12): 2274-76.

9. COSTELLO A, et al. Defining the syndrome associated with congenital Zika virus infection. Bull World Health Organ. 2016; 94(6): 406-406A.

10. DUFFY MR, et al. Zika virus outbreak on Yap Island. Federated States of Micronesia. N Engl J Med., 2009; 360: 253643.

11. EICKMANN SH, et al. Síndrome da infecção congênita pelo vírus Zika. Cad Saúde Pública., 2016; 32 (7):e00047716.

12. FAYE O, et al. Quantitative real-time PCR detection of Zika virus and evaluation with field-caught mosquitoes. Virol J., 2013; 10: 311.

13. FEITOSA IM, et al. Aspectos importantes da Síndrome da Zika Congênita para o pediatra e o neonatologista. Bol Cient Pediatr., 2016; 5(3): 75-80.

14. FRANÇA GV, et al. Congenital Zika virus syndrome in Brazil: a case series of the first 1501 live births with complete investigation [published online ahead of print June 29, 2016]. Lancet.

15. HENRIQUES CMP, et al. Desafios para o enfrentamento da epidemia de microcefalia. Epidemiol Serv Saude., 2016; 25(1): 7-10.

16. KINDHAUSER MK, et al. Zika: the origin and spread of a mosquito-borne virus [Submitted]. Bull World Health Organ. E-pub: 9 Feb 2016.

17. LEITE CN, VARELLIS MLZ. Microcefalia e a odontologia brasileira. Journal Health NPEPS., 2016; 1(2): $297-304$.

18. MARTINES RB, et al. Notes from the field: evidence of Zika virus infection in brain and placental tissues from two congenitally infected newborns and two fetal losses - Brazil, 2015. MMWR Morb Mortal Wkly Rep., 2016; 65: 159-60.

19. MIRANDA-FILHO DB, et al. Initial description of the presumed congenital Zika syndrome. Am J Public Health., 2016; 4: 598-600.

20. MLAKAR J, et al. Zika virus associated with microcephaly. N Engl J Med., 2016; 374: 951-8.

21. MOORE CA, et al. Characterizing the pattern of anomalies in congenital Zika syndrome for pediatric clinicians. JAMA Pediatr. Published online November 3, 2016.

22. MORAVA E, et al. A common mutation in the COG7 gene with a consistent phenotype including microcephaly, adducted thumbs, growth retardation, VSD and episodes of hyperthermia. European journal of human genetics: EJHG., 2007; 15(6): 638-645.

23. MORO JS, et al. Microcephaly caused by the Zika virus: dental care. RGO [Internet]. 2019 [cited 2019 Nov 26]; 67 : e2019001. Available from: http://www.scielo.br/scielo.php?script=sci_arttext\&pid=S198186372019000100500\&Ing=en. Epub Apr 25, 2019. http://dx.doi.org/10.1590/1981-86372019000013597.

24. MUSSI-PINHATA MM, YAMAMOTO AY. Infecáies congínitas e perinatais. J. Pediatr., 1999; 75(1): 15-29.

25. MUSSO D, et al. Detection of Zika virus in saliva. J Clin Virol., 2015; 68: 53-5.

26. NIMMAKAYALU M, et al. Microdeletion of 17q22q23.2 encompassing TBX2 and TBX4 in a patient with congenital microcephaly, thyroid duct cyst, sensorineural hearing loss, and pulmonary hypertension. American Journal of medical genetics., Part A. 2011; 155A (2): 418-423.

27. NUNES ML, et al. Microcephaly and Zika virus: a clinical and epidemiological analysis of the current outbreak in Brazil. J Pediatr (Rio J)., 2016; 92: 230-40.

28. OLIVEIRA CS, VASCONCELOS PFC. Microcephaly and Zika virus. J Pediatr (Rio J)., 2016; 92:103-5.

29. OLIVEIRA MELO AS, et al. Zika virus intrauterine infection causes fetal brain abnormality and microcephaly: tip of the iceberg? Ultrasound Obstet Gynecol., 2016; 47(1): 6-7.

30. ORGANIZAÇÃO MUNDIAL DE SAÚDE (OMS). Assesment of infants with microcephaly in the context of Zika virus Interim Guidance. Genebra, 2016. Available http://apps.who.int/iris/bitstream/10665/204475/1/WHO_KIKV_MOC_16.3_eng.pdf?ua=1 Acesso em: 4 Mar 2016.

31. PEREIRA SMS, et al. Zika vírus e o futuro da Odontologia no atendimento a pacientes com microcefalia. Rev Investig Bioméd São Luís., 2017; 9: 58-66.

32. PETERSEN EE, et al. Interim guidelines for pregnant women during a Zika virus outbreak - United States, 2016. MMWR Morb Mortal Wkly Rep., 2016; 65: 30-3.

33. SCHULER-FACCINI L, et al. Brazilian Medical Genetics Society - Zika Embryophathy Task Force. Possible Association between Zika Virus Infection and Microcephaly - Brazil, 2015. MMWR Morb Mortal Wkly Rep., 2016; 65: 59-62.

REAS/EJCH | Vol.12(3) | e2544 | DOI: https://doi.org/10.25248/reas.e2544.2020 Página 7 de 8 
34. SIQUEIRA WL, et al. Zika virus infection spread through saliva - a truth or myth? Brazilian Oral Research., $2016 ; 30$.

35. SOUZA ASR, et al. Alterações ultrassonográficas intraútero, crescimento da circunferência cefálica fetal e desfechos neonatais entre casos presumíveis de síndrome da Zika congênita no Brasil. Rev Bras Saúde Matern Infant., 2016; 16(1): 17-25.

36. STAPLES JE, et al. Interim guidelines for the evaluation and testing of infants with possible congenital Zika virus infection - United States, 2016. MMWR Morb Mortal Wkly Rep., 2016; 65: 63-7.

37. VAN DER LINDEN V, et al. Description of 13 Infants Born During October 2015-January 2016 With Congenital Zika Virus Infection Without Microcephaly at Birth - Brazil. MMWR Morb Mortal Wkly Rep., ePub: 22 November 2016.

38. ZANLUCA C, et al. First report of autochthonous transmission of Zika virus in Brazil. Mcm Inst Oswaldo Cruz., 2015; 110(4): 569-72. 